\title{
Use of emergency contraceptive pills among female sex workers in Swaziland
}

\author{
Eileen A Yam, ${ }^{1}$ Zandile Mnisi, $^{2}$ Sibusiso Maziya, ${ }^{3}$ Caitlin Kennedy, ${ }^{4}$ \\ Stefan Baral ${ }^{5}$
}

\begin{abstract}
${ }^{1}$ Associate, Population Council, Washington, DC, USA ${ }^{2}$ HIV/STI Manager, Swaziland National AIDS Programme, Ministry of Health, Mbabane, Swaziland

${ }^{3}$ Associate, The Rock of Hope-Lidvwala Lelitsemba, Manzini, Swaziland ${ }^{4}$ Assistant Professor, Department of International Health, Johns Hopkins Bloomberg School of Public Health, Baltimore, MD, USA

${ }^{5}$ Assistant Scientist, Department of Epidemiology, Johns Hopkins Bloomberg School of Public Health, Baltimore, MD, USA

Correspondence to Dr Eileen A Yam, 4301 Connecticut Ave NW Ste 280, Population Council, Washington, DC 20008, USA; eyam@popcouncil.org
\end{abstract}

Received 27 October 2012 Revised 18 February 2013 Accepted 26 April 2013 Published Online First 21 June 2013
To cite: Yam EA, Mnisi Z, Maziya S, et al. J Fam Plann Reprod Health Care

2014;40:102-107.

\begin{abstract}
Objectives Female sex workers (FSW) often have unprotected sex. Emergency contraceptive pills (ECP) are an important back-up method to prevent unwanted pregnancy among FSW. We examine ECP use among FSW in Swaziland.

Methods Using data from a 2011 respondentdriven sampling survey of 325 Swazi FSW, we explored the association between individual characteristics and ever having used ECP.

Results In weighted analyses, $27.5 \%$ of FSW had ever used ECP. Most (77.8\%) had ever been pregnant, among whom $48.7 \%$ had had an unwanted pregnancy and $11.7 \%$ had had an abortion. Nearly half (47.5\%) had experienced condom failure in the past month. Significant independent correlates of ECP use were younger age, higher education, higher income, having two or more children, and never having been married.
\end{abstract}

\section{Conclusions FSW who are older or of lower} socioeconomic status may not have adequate access to ECP. By better addressing these women's family planning needs, the dual goals of preventing unwanted pregnancy and preventing vertical transmission of HIV can be achieved.

\section{INTRODUCTION}

Female sex workers (FSW) are at heightened risk of both sexually transmitted infections (STIs) and unwanted pregnancy. Most interventions targeting FSW focus on HIV prevention, emphasising condom use to prevent disease transmission. When used consistently and correctly, condoms provide effective dual protection against both HIV/STIs and pregnancy. However, there is suboptimal use of condoms among FSW, the cause of which is likely multifactorial, including high frequency of sex with multiple partners, elevated susceptibility to sexual violence, substance use and low

\section{KEY MESSAGE POINTS}

- Emergency contraception pill use is common among female sex workers (FSW) in Swaziland.

- Swazi FSW engage in frequent unprotected sex and are at substantial risk of both unwanted pregnancy and HIV transmission.

- Those with lower education and income may lack access to this postcoital contraceptive method.

socioeconomic status. ${ }^{1}$ Furthermore, given their frequency of intercourse, the prevalence of condom breakage and slippage is high among FSW. ${ }^{2-4}$ In addition to their disproportionate HIV burden, ${ }^{5}$ previous studies among FSW have consistently demonstrated high levels of abortion, unwanted pregnancy and unmet need for contraception. ${ }^{6-11}$

For the past 30 years, women have used emergency contraceptive pills (ECP) as a back-up method after unprotected sexual intercourse or in cases of contraceptive failure. ${ }^{12}$ Currently, branded ECP products are registered in 140 countries, and in 60 of these countries they can be obtained at pharmacies without a prescription. ${ }^{13}$ Timely ECP use can prevent up to $95 \%$ of unwanted pregnancies ${ }^{12}$ and can serve as an entry point to encourage uptake of a regular contraceptive method. ${ }^{14}$ However, despite the clear need for postcoital contraception among FSW, little to no research has examined ECP use among these women.

We investigated ECP use among FSW in Swaziland, a country with the highest HIV prevalence in the world where approximately one-third of all 
reproductive-age adults are living with $\mathrm{HIV}^{15}$ In the general female population in Swaziland, modern contraceptive prevalence is relatively high for the southeast African region $(47.7 \%$ among married women and $62.9 \%$ among sexually active unmarried women). ${ }^{16}$ However, unwanted pregnancy is common, with just one-third of Swazi births wanted at the time of pregnancy. ${ }^{16}$ Among Swazi women of reproductive age, $25.7 \%$ have heard of ECP and $2.6 \%$ have ever used them. ${ }^{16}$ NorLevo ${ }^{\circledR}$, a dedicated progestogen-only ECP product, is sold at Swazi pharmacies, and is available at clinics of the non-profit Family Life Association of Swaziland (FLAS), an affiliate of the International Planned Parenthood Federation. The cost of NorLevo is roughly 60 emalangeni (approximately US\$7) (personal communication).

\section{METHODS}

From July to September 2011, we conducted a crosssectional survey of FSW in Swaziland using respondent-driven sampling (RDS), an adaptation of traditional snowball sampling that incorporates mathematical adjustments to account for the nonrandom nature of the sampling. ${ }^{17-20}$ Inclusion criteria included being aged 16 years or older, able to provide informed consent in either English or siSwati (the predominant local language), presenting a valid recruitment coupon, and attesting that they exchanged or sold sex for money, favours or goods in the past 12 months.

Participants responded to an intervieweradministered questionnaire that covered demographic characteristics, sexual and reproductive health knowledge and behaviours, violence, social cohesion, substance use and stigma. Specifically, the sexual and reproductive health content included questions about condom use with clients and non-commercial partners; current use of non-barrier contraception; abortion history; ever having used ECP; and ever having had an unwanted pregnancy. This article presents an analysis of the outcome of ECP use among participants, a secondary analysis of data originally collected as part of a larger biobehavioural surveillance study. Study staff gave FSW a monetary reimbursement both for their own study participation (primary reimbursement) as well as for the participation of their recruits (secondary reimbursement). After obtaining oral informed consent from participants, trained interviewers administered questionnaires at a centrally located study clinic.

Statistical analyses were conducted using Stata V.11.0 (Stata Corp., College Station, TX, USA). We first conducted exploratory data analysis to assess missingness and illogical entries. To impute the missing values for number of clients in the past month $(6.8 \%)$ we assigned the average number of clients reported by other participants who had been sex workers for the same amount of time as the woman with the missing values. No other variables were missing more than $2 \%$ of their values, and missing values for all other variables were handled by list-wise deletion. We conducted univariate analysis to describe participants' demographic characteristics and reproductive history, calculating both crude and RDS-weighted estimates. Adjusted RDS estimates attempt to account for two potential biases of the RDS methodology: the tendency for participants to recruit others like themselves (homophily) and the variation in network sizes of different individuals. To estimate standard errors for the RDS-weighted estimates we used a bootstrap method with 1000 repetitions. ${ }^{20}$ For bivariate and multivariate analyses we did not use RDS weights, given the current lack of consensus about how or whether to use weights for these more complex models using RDS data. ${ }^{20}$

Our outcome of interest was ever having used ECP, based on participants' responses to the question: "Have you ever used emergency contraception to prevent pregnancy after having unprotected sex? Emergency contraception is also known as the 'morning after pill'."

We conducted bivariate analyses using Chi-square $\left(\chi^{2}\right)$ tests to assess unadjusted correlations between the outcome and the following participant background characteristics of interest: age, marital status, education, number of children, income in the past month, and having ever received an HIV-positive diagnosis. We also calculated unadjusted bivariate associations between ever having used ECP and the following recent behaviours: current use of non-barrier contraception, always used condoms in the past month, condom failure in the past month, number of clients in the past month, and having a non-commercial partner in the past month. To identify the participant characteristics associated with ever having used ECP we conducted multiple logistic regression analysis including the previously described background characteristics in the model. We calculated variance inflation factors to assess multicollinearity, and tested model fit using the Hosmer-Lemeshow goodness-of-fit $\chi^{2}$ test.

\section{RESULTS}

Of the 339 women who presented at the study clinic, 325 met eligibility criteria and are included in this analysis. Table 1 shows the crude and weighted univariate statistics for participant characteristics and behaviours. Based on weighted estimates, the mean age was 24.1 (range 15-49) years, nearly 90\% had not completed secondary school and more than $90 \%$ were single. Average total income in the past month was US\$127. Approximately $70 \%$ of women had at least one child, and more than three-quarters had ever been pregnant. Of those who had ever been pregnant, $11.7 \%$ reported having had an abortion, and $48.7 \%$ had ever had an unwanted pregnancy. Half (51.1\%) were currently using a non-barrier modern 
contraceptive method. Less than one-quarter (22.5\%) stated that they had always used condoms in the past month. Participants had had an average of 11.6 clients in the past month, and $91.3 \%$ reported having a noncommercial partner during that period. Nearly half $(45.5 \%)$ had previously tested positive for HIV. Slightly more than one-quarter $(27.5 \%)$ had ever used ECP.

In bivariate analyses, ECP use was significantly associated with higher education levels (23.6\% among those with primary education or less compared to $33.1 \%$ among those with some secondary and 53.5\% among those with secondary or more; $p=0.002$ ). Being single was a significant correlate of ECP use, with $34.9 \%$ of single FSW having used ECP compared to $16.7 \%$ among ever-married FSW ( $p=0.029$ ). Higher income was associated with ECP use $(15.3 \%$ among those who earned less than US\$70 in the past month, 34.3\% among those who earned US\$70-140 and $42.9 \%$ among those who earned US\$141 or more; $p<0.001)$. Among those with 11 or more clients in the past month, $39.9 \%$ had used ECP compared to $25.5 \%$ among those with fewer than 11 clients $(p=0.006)$. Women who had not always used condoms in the past month were significantly more likely to have ever used ECP $(38.1 \%$ vs $15.8 \%$; $p<0.001)$. Similarly, those who had experienced condom failure in the past month were more likely to have ever used ECP (40.7\% compared to $23.1 \%$; $p=0.001$ ) (Table 2).

In adjusted analysis controlling for sociodemographic characteristics and previous HIV status, variables significantly associated with ECP use included age, marital status, education level, number of children and income. Women aged 25 years or older had a lower odds of having used ECP compared to younger women [adjusted odds ratio (aOR) 0.52; 95\% confidence interval (95\% CI) 0.29-0.94]. Single women had more than three times the odds of ECP use compared to women who had ever married (aOR 3.07; 95\% CI 1.17-8.10). Compared to women with primary education or less, women with completed secondary education were nearly four times as likely to have ever used ECP (aOR 3.88; 95\% CI 1.708.86). Higher income was significantly associated with ECP use, as those who earned US\$70-140 were more than twice as likely to have used ECP than those who earned less than US\$70 (aOR 2.58; 95\% CI $1.22-5.45)$. Likewise, those who earned US\$141 or more had a more than three-fold increased odds of

Table 1 Participant characteristics: crude and respondent-driven sampling-adjusted estimates $(n=325)$

\begin{tabular}{|c|c|c|c|c|}
\hline \multirow[b]{2}{*}{ Characteristic } & \multicolumn{2}{|c|}{ Crude estimates } & \multicolumn{2}{|c|}{ RDS-adjusted estimates } \\
\hline & $\%$ & $n$ & $\%$ & $95 \% \mathrm{Cl}^{*}$ \\
\hline Age (mean, SD) & $26.2,0.3$ & & $24.1,0.5$ & \\
\hline \multicolumn{5}{|l|}{ Education } \\
\hline Primary or less & 32.6 & 106 & 32.6 & $25.4-39.7$ \\
\hline Some secondary & 53.8 & 175 & 55.1 & $47.6-62.5$ \\
\hline Completed secondary or more & 13.5 & 44 & 12.3 & $6.5-18.2$ \\
\hline \multicolumn{5}{|l|}{ Marital status } \\
\hline Ever married/cohabited & 11.2 & 36 & 9.1 & $4.6-13.6$ \\
\hline Single/never married & 88.8 & 285 & 90.6 & $86.4-95.4$ \\
\hline \multicolumn{5}{|l|}{ Number of children } \\
\hline 0 & 24.6 & 80 & 29.2 & $21.8-36.7$ \\
\hline 1 & 30.8 & 100 & 32.1 & $24.9-39.4$ \\
\hline $2+$ & 44.6 & 145 & 38.6 & $30.8-46.4$ \\
\hline Total income in past month (US\$) (mean, SD) $\dagger$ & $157.3,9.4$ & & $127.3,9.4$ & \\
\hline Number of clients in past month (mean, SD) & $13.8,0.74$ & & $11.6,0.5$ & \\
\hline Had non-commercial partner in past month & 88.6 & 288 & 91.3 & $86.6-95.9$ \\
\hline Previously tested positive for HIV & 55.0 & 176 & 45.5 & $38.1-53.0$ \\
\hline Currently uses non-barrier modern contraception & 46.9 & 150 & 51.1 & $43.3-58.9$ \\
\hline Always used condoms in past month & 23.5 & 76 & 22.5 & $14.2-30.7$ \\
\hline Condom failure in past 30 days & 55.3 & 177 & 47.5 & $39.3-55.7$ \\
\hline Ever pregnant & 82.7 & 267 & 77.8 & $70.2-85.4$ \\
\hline Ever had an abortion $(n=266)$ & 13.2 & 35 & 11.7 & $6.3-17.1$ \\
\hline Ever had an unwanted pregnancy $(n=267)$ & 50.2 & 134 & 48.7 & $39.6-57.8$ \\
\hline Ever used ECP & 32.7 & 106 & 27.5 & $20.9-34.2$ \\
\hline
\end{tabular}

${ }^{*}$ Confidence intervals for adjusted estimates of categorical variables were constructed based on a bootstrap procedure with 1000 repetitions.

tBased on the exchange rate on 1 August 2011 (OANDA Corporation, 2012).

$\mathrm{Cl}$, confidence interval; ECP, emergency contraceptive pill; RDS, respondent-driven sampling; SD, standard deviation. 
Table 2 Bivariate analyses of participant characteristics associated with emergency contraceptive pill use $(n=324)^{*}$

\begin{tabular}{|c|c|c|c|}
\hline \multirow[b]{2}{*}{ Characteristic } & \multicolumn{2}{|c|}{ Ever used ECP } & \multirow[b]{2}{*}{$p \dagger$} \\
\hline & No $[n(\%)]$ & Yes $[n(\%)]$ & \\
\hline Age (years) $(n=324)$ & & & 0.441 \\
\hline$<25$ & $95(65.1)$ & $51(34.9)$ & \\
\hline $25+$ & $123(68.7)$ & $55(30.7)$ & \\
\hline Education $(n=324)$ & & & 0.002 \\
\hline Primary or less & $81(76.4)$ & $25(23.6)$ & \\
\hline Some secondary & $117(66.9)$ & $58(33.1)$ & \\
\hline Completed secondary or more & $20(46.5)$ & $23(52.3)$ & \\
\hline Marital status $(n=320)$ & & & 0.029 \\
\hline Married/cohabiting/divorced/separated & $30(83.3)$ & $6(16.7)$ & \\
\hline Single & $185(65.1)$ & $99(34.9)$ & \\
\hline Number of children $(n=324)$ & & & 0.094 \\
\hline 0 & $61(76.3)$ & $19(23.8)$ & \\
\hline 1 & $67(67.7)$ & $32(32.3)$ & \\
\hline $2+$ & $90(62.1)$ & $55(37.9)$ & \\
\hline \multicolumn{4}{|l|}{ Income in past month (US\$) $(n=320) \ddagger$} \\
\hline$<70$ & $72(84.7)$ & $13(15.3)$ & \\
\hline $70-140$ & $67(65.7)$ & $35(34.3)$ & \\
\hline $141+$ & $76(57.1)$ & $57(42.9)$ & \\
\hline \multicolumn{4}{|l|}{ Number of clients in past month $(n=324)$} \\
\hline$<11$ & $120(74.5)$ & $41(25.5)$ & \\
\hline $11+$ & $98(60.1)$ & $65(39.9)$ & \\
\hline \multicolumn{4}{|c|}{ Had a non-commercial partner in past month $(n=324)$} \\
\hline No & $23(62.2)$ & $14(37.8)$ & \\
\hline Yes & $195(67.9)$ & $92(32.1)$ & \\
\hline \multicolumn{4}{|l|}{ Previously diagnosed with HIV $(n=320)$} \\
\hline No & $98(68.1)$ & $46(31.9)$ & \\
\hline Yes & $116(65.9)$ & $60(34.1)$ & \\
\hline \multicolumn{4}{|c|}{ Currently uses non-barrier contraception $(n=320)$} \\
\hline No & $118(69.4)$ & $52(32.6)$ & \\
\hline Yes & $96(64.0)$ & $54(36.0)$ & \\
\hline \multicolumn{4}{|c|}{ Always used condoms in past month $(n=323)$} \\
\hline No & $153(61.9)$ & $94(38.1)$ & \\
\hline Yes & $64(84.2)$ & $12(15.8)$ & \\
\hline \multicolumn{4}{|l|}{ Condom failure in past month $(n=320)$} \\
\hline No & $110(76.9)$ & $33(23.1)$ & \\
\hline Yes & $105(59.3)$ & $72(40.7)$ & \\
\hline
\end{tabular}

*Frequencies sum by row.

tReported $p$ values are based on Chi-sqaure $\left(\chi^{2}\right)$ statistics calculated for associations between covariates and the outcome.

$\ddagger$ Based on the exchange rate on 1 August 2011 (OANDA Corporation, 2012).

$\mathrm{ECP}$, emergency contraceptive pill.

ever having used ECP (aOR 3.43; 95\% CI 1.67-7.02) (Table 3).

\section{DISCUSSION}

In a country where less than $3 \%$ of all women have ever used $\mathrm{ECP},{ }^{16}$ a very high proportion of FSW in our sample reported having used the method. Given that most FSW reported unprotected sex and could likely benefit from using ECP, it is reassuring that many participants appear to be aware of ECP and are able to access them. However, there is a socioeconomic gradient in ECP use, with use being significantly higher among those with higher education and income levels. Unfortunately, those who are less well-off may have the greatest need for ECP, yet may be less likely to use them. These women may have lower knowledge about the method, or they may simply be unable to afford it. For instance, the cost of a single ECP pack is nearly a month's income for some FSW, and for many this expense is prohibitive. HIV prevention and family planning professionals should explore strategies to ensure that ECP are 
Table 3 Multivariate logistic regression analyses of characteristics associated with emergency contraceptive pill use $(n=312)$

\begin{tabular}{|c|c|c|}
\hline Characteristic & Adjusted OR (95\% Cl) & $p$ \\
\hline \multicolumn{3}{|l|}{ Age (years) } \\
\hline$<25$ & Ref & \\
\hline $25+$ & $(0.29-0.94)$ & 0.031 \\
\hline \multicolumn{3}{|l|}{ Marital status } \\
\hline Ever married & Ref & \\
\hline Single (never married) & $(1.17-8.10)$ & 0.023 \\
\hline \multicolumn{3}{|l|}{ Highest education completed } \\
\hline Primary or less & Ref & \\
\hline Some secondary & $(0.85-2.77)$ & 0.154 \\
\hline Secondary or more & $3.88^{* *}(1.70-8.86)$ & 0.001 \\
\hline \multicolumn{3}{|l|}{ Number of children } \\
\hline 0 & Ref & \\
\hline 1 & $1.85 \quad(0.87-3.94)$ & 0.110 \\
\hline $2+$ & $(1.2-5.89)$ & 0.013 \\
\hline \multicolumn{3}{|l|}{ Total income in past month (in US\$) } \\
\hline$<70$ & Ref & \\
\hline $70-140$ & $2.58^{*} \quad(1.22-5.45)$ & 0.013 \\
\hline $141+$ & $3.43^{* *}(1.67-7.02)$ & 0.001 \\
\hline \multicolumn{3}{|l|}{ Previously received HIV-positive diagnosis } \\
\hline No & Ref & \\
\hline Yes & $(0.83-2.39)$ & 0.208 \\
\hline Hosmer-Lemeshow goodness-of-fit test & $(p=0.42)$ & \\
\hline
\end{tabular}

available to all women, particularly the poorest. Programmes and policies that address the needs of FSW - many of which include free condom distribution - should ensure that a range of contraceptive options also are available and financially accessible including ECP.

ECP use is a proxy indicator for unprotected sex. Only half of the participants in the present study were using non-barrier contraception, and a minority consistently used condoms in the past month with all sexual partners. Given the frequency of sexual intercourse among FSW, it is likely that a far greater proportion have had a need for postcoital contraception than have actually ever used it. Furthermore, some FSW may use ECP repeatedly. The literature suggests that the health risk of repeat ECP use is low, and that repeat use is safer than pregnancy, particularly in a setting where abortion is illegal and many of the ECP users may be HIV-positive. ${ }^{13}$ Nevertheless, use of ongoing, modern contraception to prevent pregnancy is far more effective than reliance on repeat ECP use. ${ }^{13} \mathrm{FSW}$ engaging in frequent unprotected sex need access to these ongoing methods, in addition to ECP as an emergency measure.

Not surprisingly, unwanted pregnancy and abortion were fairly common among participants, and a very high proportion reported that they were living with HIV. The large percentage of FSW who reported condom failure in the past month indicates that even when these women attempt to use condoms, improper use, low-quality products or limited access to appropriate personal lubricants may compromise their effectiveness. We were unable to ascertain the temporality of recent condom failure relative to past ECP use. Nevertheless, the crude association between condom failure in the past month and past ECP use suggests that condom breakage and slippage may be an important driver of ECP use among Swazi FSW. Programme planners should explore the reasons for condom failure among Swazi FSW, tailoring future interventions to address incorrect use or poor-quality products.

This study has several limitations and these findings raise questions that cannot be answered by this secondary analysis. Specifically, the cross-sectional nature of the survey prohibits us from determining the causal relationship between past ECP use and other reported behaviours such as abortion, uptake of non-barrier contraception, timing of HIV-positive diagnosis or condom use in the past month. Furthermore, we did not have information on where FSW obtained ECP, when they used them, how many times they have used them, or whether they were using any contraceptive method at the time of ECP use. Partner characteristics (such as the nature of the relationship) are also likely to influence women's decisions to use ECP, but we were unable to determine what kind of relationships the women had with the partner with whom they had unprotected sex at the time of ECP use. Finally, as with 
all surveys on sensitive behaviours, respondents may not have answered questions truthfully, and they may have felt compelled to provide socially desirable responses to questions about their sexual behaviour. Social desirability bias was likely mitigated by significant training for all staff in cultural competence in working with FSW, as well as the significant input of informal networks of FSW into all aspects of the study.

Despite these limitations, the present study sheds light on an essential preventive behaviour that has been underexplored among FSW. HIV is hyperendemic in Swaziland, and programming for FSW focuses nearly exclusively on HIV prevention and condom promotion. However, the fact that more than one-quarter of the study participants have used this postcoital, 'last resort' contraceptive method demonstrates that there is substantial need for all contraceptive methods, not just condoms. By meeting these women's family planning needs, the dual goals of preventing unwanted pregnancy and preventing vertical transmission of HIV can be achieved.

Acknowledgements The authors would like to thank the community of female sex workers who embraced this research project and chose to participate in this study. They would like to acknowledge Rebecca Miller and Darrin Adams for their leadership in the implementation of this project and Virginia Tedrow and Mark Berry for also supporting implementation. They would like to acknowledge Babazile Dlamini, Edward Okoth and Jessica Greene of Population Services International/Swaziland for their leadership in operationalising this study. They thank all the members of the Swaziland Most-at-Risk Populations (MARPS) technical working group, the Swaziland Ministry of Health and other Swazi government agencies that provided valuable guidance and helped ensure the success of this study.

Funding This work was supported by USAID Project SEARCH, Task Order No. 2, funded by the US Agency for International Development under Contract No. GHH-I-00-07-00032-00, beginning 30 September 2008, and supported by the President's Emergency Plan for AIDS Relief.

\section{Competing interests None.}

Ethics approval The Institutional Review Board at the Johns Hopkins Bloomberg School of Public Health approved this study protocol, as did the Scientific and Ethics Committee of Swaziland's Ministry of Health.

Provenance and peer review Not commissioned; externally peer reviewed.

\section{REFERENCES}

1 Shannon K, Montaner JS. The politics and policies of HIV prevention in sex work. Lancet Infect Dis 2012;12:500-502.

2 Wong ML, Chan RK, Koh D, et al. A prospective study on condom slippage and breakage among female brothel-based sex workers in Singapore. Sex Transm Dis 2000;27:208-214.

3 Qu S, Liu W, Choi K, et al. The potential for rapid sexual transmission of HIV to China: sexually transmitted diseases and condom failure highly prevalent among female sex workers. AIDS Behav 2002;6:267-275.
4 Bradley J, Rajaram SP, Moses S, et al. Why do condoms break? A study of female sex workers in Bangalore, South India.

Sex Transm Infect 2012;88:163-170.

5 Baral S, Beyrer C, Muessig K, et al. Burden of HIV among female sex workers in low-income and middle-income countries: a systematic review and meta-analysis. Lancet Infect Dis 2012;12:538-549.

6 Bautista CT, Mejia A, Leal L, et al. Prevalence of lifetime abortion and methods of contraception among female sex workers in Bogota, Colombia. Contraception 2008;77:209-213.

7 Todd CS, Alibayeva G, Sanchez JL, et al. Utilization of contraception and abortion and its relationship to HIV infection among female sex workers in Tashkent, Uzbekistan. Contraception 2006;74:318-323.

8 Elmore-Meegan M, Conroy RM, Agala CB. Sex workers in Kenya, numbers of clients and associated risks: an exploratory survey. Reprod Health Matters 2004;12:50-57.

9 Sutherland EG, Alaii J, Tsui S, et al. Contraceptive needs of female sex workers in Kenya - a cross-sectional study. Eur J Contracept Reprod Health Care 2011;16:173-182.

10 Wayal S, Cowan F, Warner P, et al. Contraceptive practices, sexual and reproductive health needs of HIV-positive and negative female sex workers in Goa, India. Sex Transm Infect 2011;87:58-64.

11 Todd CS, Nasir A, Raza, Stanekzai M, et al. Contraceptive utilization and pregnancy termination among female sex workers in Afghanistan. J Womens Health 2010;19:2057-2062.

12 Cheng L, Che Y, Gulmezoglu AM. Interventions for emergency contraception. Cochrane Database Syst Rev 2012;15: CD001324.

13 Trussell J, Raymond EG. Emergency contraception: a last chance to prevent unwanted pregnancy. September 2012. http://ec.princeton.edu/questions/ec-review.pdf [accessed 11 September 2012].

14 Lo SS, Ho PC. Changes in contraceptive choice after emergency contraception. Int J Gynaecol Obstet 2012;118:223-226.

15 Reed JB, Justman J, Bicego G, et al. Estimating national HIV incidence from directly observed seroconversions in the Swaziland HIV Incidence Measurement Survey (SHIMS) longitudinal cohort. Proceedings of the XIX International AIDS Conference, Washington, DC, USA, 22-27 July 2012.

16 Central Statistical Office (CSO) \& Macro International Inc. Swaziland Demographic \& Health Survey 2006-2007.

Mbabane, Swaziland: CSO \& Macro International Inc., 2008.

17 Heckathorn DD. Respondent-driven sampling: a new approach to the study of hidden populations. Soc Probl 1997;44:174-199.

18 Heckathorn DD. Respondent-driven sampling II: deriving valid population estimates from chain-referral samples of hidden populations. Soc Probl 2002;49:11-34.

19 Salganik MJ, Heckathorn DD. Sampling and estimation in hidden populations using respondent-driven sampling. Sociol Methodol 2004;34:193-239.

20 Schonlau M, Liebau E. Respondent-driven sampling. Stata J 2012;12:72-93. 